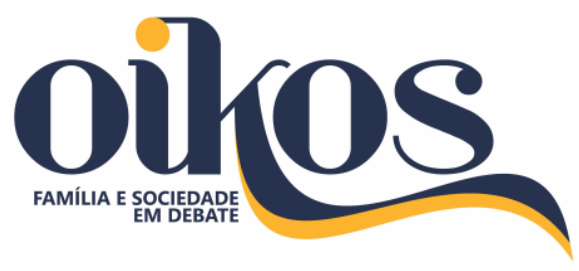

FABRÍCIO, Tamires Carolina Marques; SARAIVA, Joseana Maria; FEITOSA, Emanuel Saraiva Carvalho. Contexto sócio histórico em que surgem e evoluem as políticas de proteção à pessoa idosa no Brasil: da caridade ao direito a ILPI. Oikos: Família e Sociedade em Debate, v. 29, n. 2, p. 259-277, 2018.

DOI: https://doi.org/10.31423/oikos.v29i2.3809

PPGED

Programa de Pós-Graduação

em Economia Doméstica

\title{
Contexto sócio histórico em que surgem e evoluem as políticas de proteção à pessoa idosa no Brasil: da caridade ao direito a ILPI1
}

\section{Historical and social context in which protective policies for the elderly arise and evolve in Brazil: from charity to the right to long term care}

\author{
Tamires Carolina Marques Fabrício² \\ Joseana Maria Saraiva ${ }^{3}$ \\ Emanuel Saraiva Carvalho Feitosa ${ }^{4}$
}

\begin{abstract}
Resumo
Este artigo tem como objetivo analisar o contexto econômico, social, político e cultural em que surgem e evoluem as políticas voltadas para a pessoa idosa, sobremodo, no que concerne às Instituições de Longa Permanência para Idosos (ILPIs) no Brasil. Trata-se de pesquisa teórica embasada em revisão bibliográfica, valendo-se da contribuição dos diversos autores que tratam do fenômeno analisado. A perspectiva é apreender essa realidade, a partir do Brasil Colônia, destacando aspectos centrais e as contradições que determinam o fenômeno em cada época. Enfatiza-se a importância de se aprofundar a discussão das ILPIs, envolvendo a compreensão da percepção do Estado e da sociedade, acerca dessas instituições e dos aspectos que se interpõem a provisão da prestação desses serviços sociais com qualidade. Apesar do avanço na legislação que institui o direito ao(à) idoso(a) a um atendimento de qualidade nas ILPIs, os estudos afirmam que as condições básicas dessas instituições não atendem às exigências mínimas legais e, por conseguinte, as demandas dos(as) usuários/as, especialmente quando o foco é a assistência ao/à idoso/a menos favorecido(a).
\end{abstract}

Palavras-chave: Instituições de Longa Permanência para Idosos; Direito Social; Prestação de Serviço com Qualidade.

\begin{abstract}
This article's objective is to analyze the economical, social, political and cultural context in which policies for the elderly arise and evolve, especially concerning Long Term Care in Brazil. It is a theoretical research based on bibliography review, helping itself from the contribution of many authors who have researched this phenomenon. The perspective is to learn this reality, beginning form Colony Brazil, highlighting central aspects and contradictions which determine this phenomenon in each epoch. The importance of deepening discussions on Long Term Care, involving the comprehension of the society's and the State's perception about those institutions and the aspects which interfere in providing these social services with quality, is emphasized. Despite the advance in legislation which institutes the right of quality treatment in Long Term Care to the elderly, studies show that these institutes' basic conditions do not meet minimum legal requirements and therefore do not meet user demands, especially when the assistance to the impoverished elder is the focus.
\end{abstract}

Keywords: Long-Term Institutions for the Elderly. Social Law. Quality Service.

\footnotetext{
${ }^{1}$ Agradecimento à Fundação de Aparo à Ciência e Tecnologia de Pernambuco - FACEPE, pelo auxílio financeiro à pesquisa que deu origem a este estudo, parte da Dissertação de Mestrado desenvolvida no Programa de Pós-graduação em Consumo, Cotidiano e Desenvolvimento Social/UFRPE.

${ }^{2}$ Mestre em Consumo, Cotidiano e Desenvolvimento Social pela Universidade Federal Rural de Pernambuco (UFRPE). E-mail: tamirescarolina.tm@gmail.com

${ }^{3}$ Doutora em Serviço Social pela Universidade Federal de Pernambuco (UFPE). Professora do Departamento de Ciências Domésticas e do Programa de Pós-Graduação em Consumo, Cotidiano e Desenvolvimento Social da Universidade Federal Rural de Pernambuco (UFRPE). E-mail: joseanasaraiva@yahoo.com.br

${ }^{4}$ Graduando em Medicina pela Universidade Federal do Ceará (UFC). E-mail: emanuelscfeitosa@gmail.com
} 


\section{INTRODUÇÃO}

Os estudos mostram que a problemática das políticas de atendimento ao/À idoso/a em instituições de longa permanência para idosos no Brasil se fizeram presentes desde o período Colonial, como resultado das relações econômicas, sociais e da cultura predominante à época. $\mathrm{Na}$ busca de compreender essa realidade, o estudo se encontra estruturado em três tópicos que abordam questões fundamentais acerca do fenômeno estudado. O primeiro tópico aborda as políticas de atendimento ao/à idoso/a em instituições geriátricas, caracterizadas como asilos no século XVI - Brasil Colônia - passeando pelas instituições do Brasil Império - Século XIX, e pela trajetória das ILPIS dos séculos XX e XXI. O segundo tópico trata do avanço da legislação - na Constituição Federal (1988), na Política Nacional do Idoso (1994), no Estatuto do Idoso (2003) e na Política Nacional de Saúde da Pessoa Idosa (2006), que define e determina que essas instituições devem garantir a proteção integral ao/à idoso/a. Somando-se a essa legislação, o conjunto de normativas - Lei 10.741/2003; ANVISA / RDC 283/2005; NBR 9050/2004, que define critérios mínimos para o funcionamento, monitoramento e avaliação das Instituições de Longa Permanência para Idosos, na perspectiva de qualificar o cuidado e a prestação de serviços.

Segundo Camarano e Kanso (2010), em resposta à conjuntura de aumento da expectativa de vida e diminuição da disponibilidade de recursos familiares - particularmente da mão de obra feminina para cuidado com as pessoas idosas, há crescimento significativo do número de instituições DE atendimento aos/às idosos/as no Brasil, a partir das últimas décadas do século XX. Nesse processo, cria-se a estrutura legal referente aos direitos dos/as idosos/as e o que concerne a regulamentação dessas instituições, que define e determina o que essas instituições devem garantir para proteção integral ao/À idoso/a.

No terceiro item se apresenta e se discute os resultados dos debates em torno das contradições que se interpõem à efetivação da legislação. Na ordem da construção do problema de pesquisa, estudos realizados por Cerqueira, 2003; Creutzberg, 2007; Santos, 2003; Fabrício, et al., 2013; Fabrício e Saraiva, 2015 entre outros, afirmam que as condições básicas das ILPIs no Brasil não atendem às exigências mínimas legais e, por conseguinte, o processo de institucionalização, especialmente quando o foco são as instituições para assistência ao idoso de baixa renda, é considerado problema crônico, aparentemente sem solução na sociedade brasileira.

$\mathrm{Na}$ perspectiva de compreender essas contradições, particularizando os fatores que se interpõem à efetivação dos direitos das pessoas idosas, este artigo tem como objetivo analisar o contexto econômico, social, político e cultural em que surgem e evoluem as políticas voltadas 
para A pessoa idosa, sobremodo no que concerne às Instituições de Longa Permanência para Idosos (ILPIs) no Brasil.

Finalmente, as autoras conduzem às considerações finais, dando ênfase à importância de se aprofundar na questão das ILPIs, envolvendo a compreensão dos aspectos que se interpõem ao padrão de qualidade da prestação de serviços providos por estas instituições. Atenta-se para estimativa de crescimento da população idosa no Brasil, que prevê, para 2025, o aumento do número de pessoas com mais de 60 anos de idade superior a 21 milhões e para a institucionalização como alternativa recorrente, principalmente por parte das famílias de baixa renda, tendo em vista evitar o abandono dos/as seus/suas idosos/as. Nesse contexto, considerase, ainda, o papel do Estado como provedor social das políticas voltadas para pessoa idosa e suas contradições em relação à prestação de serviços no que concerne ao padrão de qualidade, entendido como direito de todos e não de poucos e como dever do Estado.

\section{CAMINHOS DA PESQUISA}

Trata-se de pesquisa teórica embasada em revisão integrativa da literatura, valendo-se das contribuições dos diversos autores que tratam do fenômeno analisado. $O$ intento é compreender os aspectos que se interpõem a qualidade da prestação de serviços em Instituições de Longa Permanência, tendo em vista atender as demandas de cuidados com a saúde, alimentação, higiene, repouso e lazer dos/as usuários/as, tendo em vista promover a sua saúde, autonomia, independência e bem-estar físico, psicológico e social. Nessa direção, aprofundar a compreensão acerca dessa problemática, no sentido de subsidiar o planejamento de políticas sociais voltadas para enfrentar as diferentes realidades vivenciadas pelo/a idoso/a, em especial, assegurar os seus direitos sociais, criando condições para promover a sua autonomia, independência, integração e participação efetiva na sociedade, tendo em vista evitar o risco social a que se encontram expostos os/as idosos/as.

Para tanto, realizou-se o Estado da Arte acerca do fenômeno investigado com o objetivo de mapear a produção acadêmica em diferentes campos do conhecimento, dando destaque aos aspectos e às dimensões privilegiados em diferentes contextos, épocas e lugares. $O$ levantamento de dados foi realizado nos meses de março a agosto de 2015, a partir da leitura de dissertações de mestrado, teses de doutorado, artigo em periódicos e comunicações em anais de congressos nacionais e internacionais, publicados entre os anos de 1970 a 2015, disponíveis em acervo online e bases eletrônicas de dados (LILACS da Biblioteca Virtual em Saúde (BVS); MEDLINE da PubMed; Base de Dados de Serviços Social e de Psicologia; Portal da Capes). No 
cômputo total, foram selecionados e lidos, de forma criteriosa. 15 artigos (publicados em periódicos e em Anais de congressos), duas teses Doutorado e 5 dissertações. Considerou-se ainda a pesquisa documental (legislação e normas produzida por órgãos legais - ABNT, NBR, ANVISA) e dados estatísticos e censitários produzidos por institutos de pesquisa (IBGE, Ministério da Saúde).

\section{ANÁLISE E DISCUSSÃO DOS RESULTADOS}

\section{Dos Asilos do Século XVI às ILPIs do Século XX e XXI: da caridade ao direito}

Na América Latina, particularmente no Brasil, o atendimento ao idoso em instituições geriátricas ou de longa permanência remete a épocas remotas, mais especificamente ao período Colonial. A sua origem está associada às atividades filantrópicas, caritativas e iniciativas religiosas. Segundo Creutzberg (2007) e Santos (2003, p. 624), a origem dessas instituições no Brasil, confunde-se com a história das internações de idosos/as em instituições asilares e hospitalares da Idade Média que existiam para propiciar assistência aos pobres e miseráveis.

De acordo com Christophe e Camarano (2010, p. 36) e Born (2005, s/p), o primeiro asilo para idosos no Brasil foi fundado no Rio de Janeiro, no ano de 1782, pela Ordem 3를 da Imaculada Conceição e tinha capacidade para trinta leitos. Porém, segundo Filizzola (1972, p.27), autor do livro "A velhice no Brasil", a primeira instituição para velhos do País foi a "Casa dos Inválidos", construída em 1794, no centro da Cidade do Rio de Janeiro. Inspirado na obra de Luiz XIV, que havia erguido em Paris o Hotel des Invalides, destinado aos heróis das campanhas francesas. $\mathrm{O}$ conde de Resende, Vice-Rei, defendeu a ideia de construir a mencionada instituição, que se destinava a acolher soldados com idade avançada, vindos de Portugal, e que se enc ontravam cansados dos serviços prestados à pátria, nessa condição, se faziam dignos de uma casa para descansar da velhice (ALCÂNTARA, 2004, p. 149). Com a vinda da corte, em 1808, para o Rio de Janeiro, D. João determinou que esta instituição passasse a moradia de seu médico particular, sendo os inválidos transferidos para casa de misericórdia.

Na metade do século XIX, o Brasil assiste ao fortalecimento do discurso da filantropia e do processo de constituição da medicina social, que vão alterar, de forma significativa, as práticas sobre a pobreza. Diante da decadência da escravidão e da proibição do tráfico negreiro, os pobres livres passaram a ser trabalhadores assalariados. Nesse processo, a concepção de pobreza começa a desvincular-se dos aspectos morais, religiosos e da caridade. Nesse processo, segundo Groisman (1999, p. 180), o discurso filantrópico e médico-higienista vai 
criticar a caridade e propor um projeto civilizador, sendo a população indigente, mendigos e vadios, mais intensamente reprimida.

A ação dos higienistas vai recair sob o modo de vida das classes pobres, que passa a ser visto como potencialmente perigoso, sobretudo, os pedintes, que representavam ameaça à salubridade da cidade. Suspeitava-se que os locais de concentração de mendigos também emanassem os terríveis miasmas que colocavam em perigo a saúde da população. Os mendigos e vadios tornaram-se, então, agentes propagadores de doenças e sua livre existência não seria mais tolerada (GROISMAN, 1999, p. 181)

A partir de 1850, a investida social sobre a população de rua se acentua. No Rio de Janeiro, em agosto de 1854, fundava-se o "Asilo de Mendicidade", conhecido como "albergaria", destinado a receber e dar agasalho a todos os mendigos, entre eles, muitos eram velhos, encontrados na rua, na frente de Igrejas e praças. Os mendigos ganhavam, assim, uma instituição especial, cujo fim era recolher e realizar uma certa triagem sobre a população indigente, separando doentes e inválidos de delinquentes.

Segundo Santos (2011, p.11), em 1968, por meio do decreto $n^{\circ} 244 / 41$, foi criado o "Asilo dos Inválidos da Pátria", que tinha como finalidade amparar os militares da terra que se invalidaram em campanhas ou serviços. Continuava o predomínio da caridade cristã como norma orientadora das obras sociais. Para se ter ideia, o novo asilo funcionaria no mesmo local onde antes funcionou o hospital de lázaros, enfermaria de coléricos e doentes de febre amarela e antigo convento dos Franciscanos, localizado na Ilha de Bom Jesus, ao lado da Ilha da Sapucaia, onde se depositava o lixo e desaguava parte dos esgotos da cidade, infestado de moscas, baratas, ratos e mau cheiro insuportável (SANTOS, 2011, p.12), refletindo a situação de pobreza e abandono de uma parcela significativa dos/as velhos/as pobres à época.

Em 1879, foi inaugurado o lar da Mendicidade, com o objetivo de abrigar crianças, pessoas abandonadas, ociosas, indigentes, inválidas, velhos e alienados, que não podiam ser recebidos no Hospício Dom Pedro II. Apesar da segmentação com base na faixa etária e na condição em que as pessoas se encontravam, não havia distinção clara entre as necessidades de cuidado e o tratamento específico que deveria ser oferecido a cada indivíduo, todos recebiam o mesmo atendimento, independentemente de serem mendigos, velhos ou crianças (GROISMAN, 1999). A história dessa instituição foi curta, tendo os seus residentes sido transferidos para a Santa Casa no início do século seguinte, e a chácara que lhe serviu de sede foi doada por Dom João VI ao seu médico, como pagamento de dívida. (FILIZZOLA, 1972).

No final do século XIX, o Rio de Janeiro era palco de transformações de ordem política, econômica e social, - de intensa imigração, a abolição da escravatura e proclamação da 
república. É nesse cenário que nova instituição surge em 1890, o Asilo São Luiz, para a Velhice Desamparada, primeira instituição da cidade cuja finalidade era acolher exclusivamente à velhice. A separação da velhice desamparada das outras categorias sociais levou maior especialização das ações de assistência social, crianças para os asilos de órfãos ou instituições congêneres, loucos para o Hospício Nacional, vadios para a Casa de Correção e, finalmente, velhos para o asilo de velhos.

Para Lima (2011, p. 62), o Asilo São Luiz não foi uma instituição qualquer, mas, sim, marcou uma nova era no que diz respeito ao amparo da velhice brasileira. Embora de caráter privado, fundado por um proeminente homem de negócios da sociedade carioca, o Visconde Ferreira de Almeida, a instituição recebia subvenções públicas e contava com o apoio das freiras Franciscanas, que cediam irmãs de caridade para cuidar dos asilados na condição de voluntárias. Para se ter ideia, em pouco mais de três décadas ampliou a sua capacidade de atendimento de 45 leitos iniciais, em 1892, para 260 leitos, em 1925. Com o dinheiro das subvenções e dos inúmeros donativos que a instituição recebia da sociedade, ampliou e modernizou as instalações, numa série de obras que chamavam a atenção para o grande empreendimento Nessa condição, diferenciando-se das demais instituições e prosseguindo na óptica filantrópica assistencialista típica do início do século XIX, abrigava não só idosos pobres, mas também aqueles que tinham recursos financeiros.

Para Groisman (1999, p. 71), o rápido desenvolvimento do Asilo São Luiz acompanhou a evolução econômica e social do país e o surgimento de novas representações sociais acerca da velhice. Nesse sentido, o traço mais marcante do trabalho social e caritativo, desenvolvido na entidade, era dar visibilidade aos idosos como segmento populacional com características distintas dos demais segmentos, objeto de preocupação e de cuidados sociais por parte da instituição.

No início do século $X X$, o campo de atuação da assistência social era terreno bastante complicado, confundia-se, frequentemente, pobreza com vadiagem. Segundo Escorsim (2008), o atendimento das repercussões da pobreza e da miséria era entendido como "caso de polícia", na década de 20. Nesse contexto, ao mesmo tempo que as instituições filantrópicas floresciam, a população nutria sentimentos bastante ambivalentes em relação à pobreza urbana. Groisman (1999, p. 72-75) explica que era necessário definir aqueles que realmente mereciam e deveriam ser assistidos, segundo critérios que visassem a preservação da ordem e combatessem a ociosidade e os "vícios" que caracterizavam a vadiagem. Nessa medida, os velhos que deveriam ser assistidos seriam diferenciados dos que faziam da mendicância uma "profissão", sendo, por 
conseguinte, tratados como vítimas de circunstâncias que os isentavam de responsabilidade pela sua miséria.

Se não havia o entendimento da causa da pobreza dos/as idosos/as carentes e abandonados/as, também não havia culpados pelo desamparo na velhice, a responsabilidade pelo seu amparo deveria ser obrigação da sociedade. Faltava, contudo, o entendimento de que o processo de produção capitalista é que determinaria o lugar social dos idosos, conforme ocupação ou não no processo produtivo. Segundo Escorsim (2008, s/p), a propriedade privada dos meios de produção e a mercantilização, como substrato da sociedade capitalista, determinam o lugar social daqueles trabalhadores inseridos no processo produtivo dos quais se extrai a mais-valia, e daqueles cuja força de trabalho não interessa imediatamente ao capital e, portanto, cumpriam a função de exército industrial de reserva. Relegados do processo produtivo, restava-Ihes apenas a caridade, a benemerência, e a filantropia como resposta às suas indigências.

Embora a institucionalização do/a idoso/a seja fenômeno antigo e esteja presente em todos os contextos da humanidade, as políticas de assistência social a esse segmento têm sido sistematicamente negligenciadas, sobretudo, aos pobres e miseráveis. Na história dessas instituições, o que é bastante visível e documentado é a participação intensa das associações religiosas, filantrópicas e de caritativas nessa atividade, com cunho eminentemente assistencialista, de amparo aos miseráveis. Esse contexto vai refletir o sentimento de pena movido, espontaneamente, pela boa vontade da sociedade. Quando praticada pelos governos, como providência administrativa emergencial, a assistência ao idoso visa somente reparar carências gritantes de pessoas em estado de pobreza absoluta e extrema miséria (PEREIRAPEREIRA, 2002, p.115-116).

Por volta de 1940, de acordo com Novaes (2003, s/p), as instituições de atendimento ao idoso deixam de desempenhar apenas o papel de mera caridade, de ajuda e amparo aos mais necessitados, para se tornar fonte de arrecadação, caracterizando novo modelo de assistência social à institucionalização do/a idoso/a. Por conseguinte, aqueles que têm condições financeiras favorecidas passam a pagar pelos serviços prestados nessas instituições.

Uma mudança percebida a partir desse momento diz respeito aos/às usuários/as institucionalizados/as, na medida em que não mais eram constituídos apenas pelos desamparados que careciam de assistência, passando a abranger velhos, independentemente de condição social. Segundo Lima (2011, p. 65), era comum a existência de quartos particulares para velhos que tinham condição de pagar para permanecerem no asilo e ter um abrigo, no mínimo, seguro. Para se ter uma ideia dessa nova conjuntura, nos anos de 1950, a Santa Casa 
de Misericórdia de São Paulo chegou a dar assistência a mendigos e, em conformidade com o aumento de internações para idosos, passou a definir-se, em 1964, também como instituição gerontológica (BORN, 2005 apud POLLO; ASSIS, 2008).

No transcorrer do século XX, os asilos passaram a figurar cada vez menos nas notícias de jornal. A fama conferida à velhice asilada no início do século foi substituída, paulatinamente, pela invisibilidade; a institucionalização da velhice não seria mais gerenciada apenas por homens de bom coração, dispostos a praticar a filantropia e a caridade, mas por homens com interesses comerciais, mesmo quando praticando a filantropia. As instituições filantrópicas transformaramse num negócio lucrativo e proliferaram em abundância, sobremaneira no Brasil.

$\mathrm{Na}$ década de 1970 surgem diversos movimentos sociais no Brasil de iniciativa das classes populares, apontando novas formas de participação social e política, constituídos com o objetivo DE protestar contra as crises econômicas, as desigualdades sociais, reivindicando do Estado a redistribuição de recursos, mais empregos e questionando a falta de políticas públicas efetivas, exercendo sobre o Estado um certo controle.

Nessa mesma década, baseado na lei no 6.119/74, o Instituto Nacional de Previdência Social (INPS) passou a apoiar os centros de convivência enquanto lugares de socialização para idosos, como alternativa para promover participação social e a caridade aos indivíduos com mais de 60 anos, com condições de convivência grupal, podendo ser ou não acompanhado de algum cuidador e estes começaram a se organizar em associações (RODRIGUES, 2005, p. 84-90).

O ano de 1976 é considerado um marco de uma nova era em relação às políticas públicas voltadas à velhice. O INPS cria o primeiro Programa de assistência ao idoso, PAI - Programa de Assistência ao Idoso, cujo objetivo consistia na organização de grupos de convivência para idosos previdenciários, os quais funcionava nos Postos de atendimento desse Instituto. Com a reforma da Previdência, em 1977, criou-se o SINPAS - Sistema Nacional de Previdência e Assistência Social, e o PAl passou a ser administrado pela Fundação Legião Brasileira de Assistência com atendimento em todo o território nacional. De caráter assistencialista, a atuação acontecia em dois níveis: a) direto, cuja ações se realizava nas próprias instalações e com pessoal técnico. A finalidade se constituía em dar assistência social por meio dos centros sociais, postos de distribuição de material, alimentos. b) indireto: a LBA - Legião Brasileira de Assistência - realizava convênios com asilos, pagando um per capita x por um certo número de vagas para idosos, que ela selecionava e os encaminhava aos asilos conveniados, supervisionados por Assistentes Sociais da própria LBA (RODRIGUES, 2001 p.151).

Em função das inúmeras denúncias acerca das deficiências e precarização das instituições de atendimento a idosos, o governo federal elaborou, em 1976, o primeiro documento 
contendo algumas diretrizes para uma política social voltada para a população idosa, editada pelo Ministério da Previdência e Assistência Social (MPAS). O referido documento foi fundamentado nos resultados obtidos em três seminários regionais, realizados em São Paulo, Belo Horizonte e Fortaleza, além de outro de âmbito nacional, que objetivaram identificar as condições de vida do idoso brasileiro e as condições das instituições de apoio assistencial para atender às suas demandas e necessidades (LIMA, 2011, p. 43).

Desses Seminários, resultou acervo de informações sobre a situação do idoso na sociedade brasileira, o qual, analisado e organizado pela então Secretaria de Assistência Social, do Ministério da saúde, deu origem a um documento, extremamente importante, intitulado: Políticas para a $3^{\text {a }}$ Idade - Diretrizes Básicas (o qual apresenta as linhas básicas de uma política de assistência e promoção social ao idoso).

Com o processo de redemocratização do país, e, por conseguinte, com a promulgação da Constituição de 1988, os direitos e garantias fundamentais, juntamente com os direitos civis e políticos, passaram a ser a bandeira do Estado Democrático de Direito. Isto significa que a regulamentação de leis especiais, que deveriam garantir a dignidade da pessoa humana, as relações de consumo e o direito a acesso a tratamento especial por parte dos hipossuficientes, em todas as esferas de direito, torna-se a preocupação de juristas e doutrinadores.

Os projetos apresentados pelos parlamentares, com o escopo de regular estes direitos, advindos da Carta Magna, tornam-se prioridade, nos gabinetes dos parlamentares, no enquadramento da conjuntura política dos anos 80 e 90.

Segundo Camarano e Kanso (2010), a partir das últimas décadas do Século XX, o número de instituições destinadas ao atendimento de idosos/as no Brasil começou a crescer, ao mesmo tempo em que foi sendo criada estrutura legal para regular suas atividades. Esse crescimento vai acontecer como resposta a uma conjuntura que apresentava aumento da expectativa de vida e contraditoriamente diminuía a disponibilidade de recursos familiares para o cuidado com as pessoas idosas.

A imagem que existia sobre a velhice, no inicio do século $X X$, também sofre mudanças. Para Groisman (1999, p. 78), o surgimento da "terceira idade" pode ser considerado como tentativa de rompimento com as imagens negativas da velhice que, como foi visto, predominavam no início do século. Diferentemente da "velhice", a "terceira idade" se caracterizaria por ser a fase da vida em que as pessoas aproveitariam intensamente o seu tempo na busca de realizações pessoais. O lazer, os cuidados com o corpo e a saúde, a ampliação do círculo social e até mesmo o exercício da sexualidade parecem estar presentes nessas novas representações sociais do 
envelhecimento. Os termos são importantes: a "velhice" é substituída pela "terceira idade", e os "velhos" tornam-se "idosos".

Segundo Birman (1995, p.23), a noção de "terceira idade" torna-se sinônimo dos "jovens velhos", os aposentados dinâmicos que se inserem em atividades sociais, culturais e esportivas. É o "velho" sendo substituído pelo novo, consequência de imposição da mídia e da sociedade que enaltece aquele que é jovem, desconsiderando o envelhecimento como uma fase da vida, única e importante e que traz modificações biopsicossociais que devem ser respeitadas.

\section{Legislação e direitos dos/as idosos/as no Brasil: avanços e retrocessos}

Estudos como os de Lima (2011) e Rodrigues (2005) mostram que, anterior à década de 70, foram criadas instituições de caráter assistencial, como a Santa Casa de Misericórdia, bem como outros antecedentes, tais como os montepios civis e militares, o regulamento da aposentadoria dos empregados dos correios com idade mínima de 60 anos, e ainda, em 1930, a política de bem-estar social que incluía a previdência social, saúde, educação e habitação.

O Século XX também é palco de iniciativas relacionadas ao reconhecimento dos direitos dos/as idosos/as. Em 1948 a Assembleia Geral das Nações Unidas promulgou a Declaração Universal dos Direitos Humanos; este documento, além de afirmar que "todas as pessoas nascem livres e iguais em dignidade e direitos", define, em seu artigo 25 , os direitos universais dos idosos:

Segundo a Declaração dos Direitos Humanos no art. 25, $\S 1^{\circ}$, toda pessoa tem direito a um padrão de vida capaz de assegurar a si e a sua família saúde e bem-estar, inclusive alimentação, vestuário, habitação, cuidados médicos e os serviços sociais indispensáveis, e direito à segurança, em caso de desemprego doença, invalidez, viuvez, velhice ou outros casos de perda dos meios de subsistência em circunstâncias fora do seu controle.

Nos anos 70, o Instituto Nacional de Previdência Social (INPS), com base na lei no 6.119/74, passou a apoiar os centros de convivência enquanto lugares de socialização para idosos/as e estes começaram a se organizar em associações (RODRIGUES, 2005, p. 84-90).

Camarano e Pasinato (2004) afirmam que o início das políticas públicas para idosos/as, em âmbito global, só vai acontecer com a 1aㅗ Assembleia Mundial sobre o Envelhecimento, em Viena, no ano de 1982, cujo resultado foi um plano global de ação, que gerou objetivos como: garantir segurança econômica, social, autonomia e integração dessa população ao processo de desenvolvimento das nações, inclusive percebendo o idoso como um potencial consumidor. 
Dentre as leis criadas em obediência às normas elencadas no artigo $5^{\circ}$, da Constituição Federal de 1988 - que trata dos direitos e garantias fundamentais, podem-se destacar o Código de Defesa do Consumidor, o Estatuto do Idoso e a Política Nacional do Idoso, dentre outras. Segundo Lima (2011, p. 44), o caráter social e assistencial da Constituição Federal de 1988 abriu caminho para a efetivação de avanços na assistência social no Brasil.

Para Pinto e Simson, as regulamentações criadas nas últimas décadas refletem diretamente a visão de mundo e cidadania que preside o texto da Constituição Federal de 1988,

na qual os/as idosos/as passaram a ser definidos como sujeitos de direitos diferenciados, e, portanto, merecedores de especial atenção. Esta atenção se efetiva através da construção de uma rede de seguridade social, que tem como apoio um tripé composto por Previdência, Saúde e Assistência Social (PINTO E SIMSON, 2012, s/p).

Nestas áreas, vem sendo criado arcabouço legal de proteção aos idosos/as, entendido como direito de todos e dever do Estado. Na Constituição de 1988, o apoio aos idosos passa explicitamente a ser dever da família, do Estado e da sociedade. Na prática, porém, a família continuou sendo a principal responsável por este apoio e a maioria carece de condições econômicas para viabilizá-lo. Segundo Silva et al., (2013), enquanto nos países desenvolvidos o envelhecimento da população ocorreu conjuntamente com melhorias da condição e qualidade de vida dos idosos, nos países em desenvolvimento, esse crescimento ocorreu de forma rápida, carente de organização social e de saúde suficientemente capaz de atender às novas demandas e necessidades emergentes da população idosa.

No ano de 1989, o Ministério da Saúde, considerando o aumento da população de idosos no Brasil, a associação do envelhecimento a condições sociais e sanitárias que demandam atendimento específico, bem como a necessidade de serem estabelecidas normas para que 0 atendimento ao idoso em instituições fosse realizado dentro de padrões técnicos elevados, publicou a Portaria Federal no 810/89, que determina a normatização do funcionamento padronizado de instituições ou estabelecimentos de atendimento ao idoso. Com base nessa portaria, eram aprovadas as normas e os padrões para o funcionamento de casas de repouso, clínicas geriátricas e outras instituições destinadas ao atendimento de idosos, a serem observados em todo o Território Nacional.

Dando continuidade a esse processo, em 1990, a lei Lei n.. 8.080 propiciou a formulação da primeira Política Nacional de Saúde (PNS), que apresenta as condições para a promoção, proteção e recuperação da saúde, bem como dispõe acerca da organização e do funcionamento dos serviços. Com base nessa lei, outras legislações foram formuladas ao longo do tempo, de 
caráter setorial, particularizando grupos ou modalidades específicas de atenção à saúde. Nesse termos, a Política Nacional de Saúde do Idoso (PNSI) é uma das políticas setoriais que vieram a se consolidar a partir da PNS.

No ano de 1993, foram promulgados o Estatuto do Ministério Público da União e a Lei Orgânica de Assistência Social - LOAS (Lei 8.742/1993), reconhecida como política de seguridade social, responsável pela garantia de proteção social não contributiva à população socialmente mais exposta a riscos e pela criação de instâncias de entendimento, compromisso e compartilhamento de experiências nos três níveis governamentais, sob a forma de conferências. Um aspecto que se sobressai na LOAS é a proteção aos cidadãos na velhice no âmbito da previdência Social. Esta proteção se traduz, sobremaneira, na garantia de um salário mínimo mensal - Benefício de Prestação Continuada (BPC) - para isso o/a idoso/a deve comprovar falta de recursos para prover seu sustento.

De acordo com Lima (2011, p. 45), dando prosseguimento às diretrizes lançadas pela Constituição Federal de 1988 e fortemente influenciada pelo avanço dos debates internacionais sobre a questão do envelhecimento, foi aprovada no Brasil, em 4 de janeiro de 1994, a Lei 8.842, que instituiu a Política Nacional do Idoso (PNI). Essa política consiste em um conjunto de ações governamentais que tem por objetivo assegurar os direitos de cidadania dos idosos, partindo do princípio fundamental de que este é um sujeito de direitos e deve ser atendido de maneira diferenciada em cada uma das suas necessidades: físicas, sociais, econômicas e políticas. Para a sua coordenação e gestão foi designada a Secretaria de Assistência Social do então MPAS, atualmente Ministério do Desenvolvimento Social e Combate à Fome (MDS).

Em 1999, o Ministério da Saúde elaborou a Política Nacional de Saúde do Idoso (PNSI), cujos eixos principais são: a prevenção, dentro das ideias da promoção de saúde e do atendimento multidisciplinar, o foco na capacidade funcional e a participação popular. Essa política se efetiva pelas ações do Sistema Único de Saúde (SUS) e do Programa de Saúde da Família (PSF), regulamentado posteriormente.

Ainda em 1999, a Diretoria Colegiada da Agência Nacional de Vigilância Sanitária ANVISA, considerando o interesse manifestado pelas diversas entidades e representações da sociedade, relativo ao Regulamento Técnico para o funcionamento de Instituições Residenciais sob Sistema Participativo e de Longa Permanência para Idosos, aprova o Decreto no 3.029/99, o Regulamento Técnico para o funcionamento de Instituições Residenciais sob Sistema Participativo e de Longa Permanência para Idosos.

Foi criado, também, em 2002 o Conselho Nacional dos Direitos do ldoso (CNDI), Esse conselho é um órgão superior de natureza e deliberação colegiada, permanente, paritário e 
deliberativo, integrante da estrutura regimental do Ministério dos Direitos Humanos. Cabe a ele elaborar as diretrizes para a formulação e implementação da Política Nacional da Pessoa Idosa. O CNDI contabilizou avanços importantes à medida que contribui com ações importantes para criação do Estatuto da Pessoa Idosa, instrumento que assegura direitos especiais e institui programas de promoção da qualidade de vida desta parcela da população.

Evoluindo nesta perspectiva, é promulgado, em 200, o Estatuto do Idoso (Lei $n^{\circ} 10.741$, de $1^{\circ}$ de outubro de 2003), destinado a regular os direitos assegurados às pessoas com idade igual ou superior a 60 anos. $O$ idoso, a partir da promulgação dessa lei, passa a gozar de todos os direitos fundamentais inerentes à pessoa humana, sem prejuízo da proteção integral de que trata esta Lei, assegurando-lhes, por lei ou por outros meios, todas as oportunidades e facilidades para a preservação de sua saúde física e mental e seu aperfeiçoamento moral, intelectual, espiritual e social, em condições de liberdade e dignidade. É clara a obrigação da família, da comunidade, da sociedade e do Poder Público de assegurar ao idoso, com absoluta prioridade, a efetivação do direito à vida, à saúde, à alimentação, à educação, à cultura, ao esporte, ao lazer, ao trabalho, à cidadania, à liberdade, à dignidade, ao respeito e à convivência familiar e comunitária. Ressalta-se aqui a garantia de acesso às redes de serviços de saúde e de assistência social locais, incluindo atendimento asilar, quando o idoso não a possuir ou carecer de condições de manutenção da própria sobrevivência e cuidados pela família.

É importante ressaltar que o Estatuto do Idoso reuniu em uma única e ampla peça legal muitas das leis e políticas já aprovadas, e incorporou novos elementos e enfoques, dando tratamento integral, com visão de longo prazo, ao estabelecimento de medidas que visam proporcionar o bem-estar aos idosos brasileiros (LIMA, 2011, p. 49).

Com o crescimento, em termos populacionais, do segmento acima de 60 anos de idade, há também o aumento da demanda por ILPIs, bem como o aumento dos problemas vivenciados pelos idosos nessas instituições. Estudos evidenciam (MOREIRA, 2007, p. 522.) situações de abandono e de descaso vividas por muitos idosos brasileiros que residem em instituições asilares. Essa situação conduziu à organização de associações e movimentos sociais para reivindicar a efetivação da garantia dos direitos dos idosos a um atendimento de qualidade em seus vários aspectos. Com base nessa premissa, o estatuto define a fiscalização das instituições de longa permanência a cargo dos municípios, da ANVISA e do Ministério Publico.

Assim, considerando a necessidade de definir os critérios mínimos para o funcionamento e avaliação das Instituições de Longa Permanência para Idosos, bem como os respectivos mecanismos de monitoramento, é formulada, em 2005, a RDC n² 283. Dentre estes mecanismos podem-se destacar: as condições gerais em relação à atenção ao idoso, a organização do 
ambiente e da infraestrutura física, material e humana, processos operacionais, saúde, alimentação, higiene e vigilância epidemiológica.

Em 2006, a Portaria/GM no 399 publica as Diretrizes do Pacto pela Saúde, nas quais estão contempladas três dimensões: pela Vida, em Defesa do SUS e de Gestão. A Saúde do Idoso aparece como uma das prioridades no Pacto pela Vida, o que significa que, pela primeira vez na história das políticas públicas no Brasil, a preocupação com a saúde da população idosa brasileira é explicitada (BRASIL, 2010, p. 11).

Neste documento é assumido compromisso entre os gestores do SUS em torno de prioridades que, de fato, apresentem impacto sobre a situação de saúde da população brasileira, incluindo a população idosa. Assim, a Saúde do Idoso tornou-se uma das prioridades do Pacto Pela Vida, como consequência da dinâmica demográfica do país. Em tal perspectiva é visto o conjunto de diretrizes e ações contidas no Pacto pela Vida/Saúde do Idoso, que visa subsidiar os Termos de Compromisso de Gestão Estaduais e Municipais, na área da atenção à saúde da população idosa Ministério da Saúde (BRASIL, 2010, p. 11).

A partir do exposto, constata-se que a institucionalização do(a) idoso(a) é, portanto, demanda social histórica, reivindicada pelas populações urbanas e rurais, independentemente de se tratarem de instituições públicas ou privadas, com ou sem fins lucrativos, governamentais ou não governamentais. Nessa direção, a legislação determina que devem garantir infraestrutura física e material e funcionar de forma adequada, tendo em vista propiciar condições de saúde e bem-estar social a essa população, em condições de liberdade, dignidade e cidadania.

Contudo, pesquisas têm mostrado (CERQUEIRA, 2003; CREUTZBERG, 2007; SOUSA, 2008) que o processo de institucionalização no Brasil, especialmente quando o foco são instituições para assistência ao idoso de baixa renda, é considerado problema crônico, aparentemente sem solução na sociedade brasileira. Apesar da Constituição Federal, assim como outros documentos formais, ressaltar que o dever de assegurar esse tipo de equipamento e de serviço coletivo com qualidade não é apenas do Estado, mas, também, da sociedade, a disponibilidade de oferta de ILPIs ainda é muito baixa.

Considerando que a estimativa de crescimento da população com mais de 60 anos de idade até 2025 será superior a 27 milhões de pessoas e que, conforme mostram os estudos, a institucionalização tem sido alternativa recorrente, principalmente por parte das famílias de baixa renda, tendo em vista evitar o abandono dos seus idosos, essa questão é preocupante. Pesquisas evidenciam (FERREIRA, 2007; RIBEIRO E SCHUTZ, 2007; LIMA, 2011; FABRÍCIO E SARAIVA, 2015, dentre outros) que, além da baixa oferta, a qualidade da prestação de serviços provida pelo Estado e pelas instituições particulares sem fins lucrativos não é a desejável, o 
problema em relação a essa questão é muito sério e envolve variados fatores que precisam ser melhor estudados.

Esta situação tem exposto parcela significativa de idosos/as a cotidiano apático, depressivo e insalubre, o qual não propicia, por sua vez, a manutenção ou melhoria de sua qualidade de vida e, consequentemente, o bem-estar físico e social dos(as) envolvidos(as) (CERQUEIRA, 2003; SILVA, et al., 2006; RIBEIRO E SCHUTZ, 2007; SOUSA, 2008). Segundo Bertelli (2006), o espaço físico e social habitado pelos idosos/as em instituição de longa permanência depende de vários fatores que podem incentivar, deprimir, cuidar ou colocar em risco a pessoa, no caso o/a idoso/a que faz uso dele.

Segundo Pollo e Assis (2008), isso se deve à contextualização em que essas instituições foram criadas e à forma como continuam sendo concebidas. Historicamente, surgiram para atender pessoas em situação de pobreza, com problemas de saúde e sem suporte social. Para Costa e Mercadante (2013), falar de idoso institucionalizado, ou daquele que mora em asilo ou em ILPI, evoca uma imagem negativa de "pobreza" e "abandono", porque essas instituições, na sua maioria, foram e continuam sendo mantidas por associações religiosas ou por outras organizações de benemerência que têm como objetivo o amparo dos idosos pobres ou miseráveis em situação de abandono.

Estes estudiosos ressaltam ainda que, embora se identifiquem muitas instituições particulares com assistência relativamente boa para atender idosos, ainda assim apresentam condição em que se associa a ideia de abandono à velhice. Quer se tratem de instituições públicas, vinculadas ao Estado, ou das que vivem de doações públicas e/ou privadas, todas lidam com a realidade muito ligada à situação financeira e com denominador comum implicado com a ideia de abandono e por conseGuinte de precarização da prestação de serviços.

\section{CONCLUSÃO}

O que se constata neste estudo são significativas contradições, isto significa afirmar que, apesar do avanço na legislação, que reconheceu o/a idoso/a como sujeito de direito, e independentemente do seu caráter, os estudos apresentam a existência de precarização enorme das ILPIs, não apenas no que concerne à infraestrutura física e material, mas também no que diz respeito ao alto índice de idosos/as mal cuidados/as e abandonados/as nesses locais, em virtude da qualidade do atendimento prestado as pessoas idosas que vivem em instituições de longa permanência têm poucas oportunidades de participar de atividades recreativas ou de lazer, 
contribuindo para o seu isolamento, adoecimento e risco social, isto porque o seu direito lhe é negado.

Considerando que esta é a população que mais cresce e que ao mesmo tempo possui os maiores índices de dependência física, déficits cognitivos e de dificuldades associadas ao autocuidado e à manutenção de uma vida independente, torna-se urgente pensar em modalidades de cuidados de longa duração em instituições de longa permanência que possam responder às necessidades psicossociais e de saúde dos/as idosos/as, associadas ao envelhecimento com qualidade de vida, que atendam os/as idosos/as em todas as suas demandas e necessidades.

Os achados refletem ainda, a desresponsabilização do Estado na provisão dos equipamentos coletivos de atendimento ao idoso/a e o predomínio da participação da sociedade, sobremodo, da igreja e das instituições sem fins lucrativos, na manutenção das ILPIs. Confirmam, portanto, a existência de postura inerte do Estado frente às demandas dos/as idosos/as que precisam ou que já se encontram institucionalizados/as, cooperando, dessa forma, para que a relação de cuidado resulte em risco social para os/as idosos/as, pela negação do direito dentro dos padrões exigidos pela legislação.

As análises realizadas neste estudo mostram ainda como o país não está preparado para enfrentar os problemas atuais e os advindos do crescimento da população idosa, e isso é muito preocupante, considerando que esse segmento envelhece em escala progressiva. Trata-se de questão fundamental a ser priorizada na perspectiva do estabelecimento de direitos iguais, numa sociedade desigual e para grupos específicos.

Nesse entendimento, a velhice deve deixar de ser questão de ordem apenas privada e preocupação da assistência filantrópica, mas ser, sobretudo, preocupação do Estado como provedor social. Reforça-se, ainda, o papel do Estado no investimento em programas de suporte ao(à) idoso(a), a fim de garantir a qualidade nos serviços prestados, além de condições de segurança e dignidade aos residentes, na perspectiva de evitar o Risco Social.

\section{REFERÊNCIAS}

AGÊNCIA NACIONAL DE VIGILÂNCIA SANITÁRIA (ANVISA). Diário Oficial da União. Resolução da Diretoria Colegiada n² 283, de 26 de setembro de 2005. Brasília, 2005. Disponível em: www.portalsaude.gov.br. Acesso em: 10 de maio de 2015.

ASSOCIAÇÃO BRASILEIRA DE NORMAS TÉCNICAS NBR 9050: 1994. Acessibilidade de pessoas portadoras de deficiências a edificação, espaço mobiliário e equipamentos urbanos. Associação Brasileira de Normas Técnicas. Rio de janeiro: ABNT, 1994. 
ALCÂNTARA, Adriana de Oliveira. Velhos institucionalizados e família: entre abafos e desabafos. São Paulo: Alínea; 2004. Google

BALTES, Pou; SMITH, Jaqui. Novas fronteiras para o futuro do envelhecimento: da velhice bem sucedida do idoso jovem aos dilemas da quarta idade. A Terceira Idade. v.17, n. 36, p.731, 2006.

BORN, Tomiko. O que é uma ILPI? Portal do envelhecimento, 29 de nov.2005.

BERTELLI, Antônio R; PALMEIRA, Moacir G. S; VELHO, Otávio Guilherme. Estrutura de classes e estratificação social. Rio de Janeiro. Jorge Zahar, 2006. p. 84-93.

BRASIL. Lei no 10.471, de 10 de outubro de 2003. Dispõe sobre o Estatuto do Idoso e dá outras providências. Diário Oficial da União, Brasília, 5 jan. 1994.

CAMARANO, Ana Amélia; KANSO, Solange. As instituições de longa permanência para idosos no Brasil. Revista Brasileira de Estudos Populacionais, v.27, n.1, p.233-235, 2010. Google

CAMARANO, Ana Amélia; PASINATO, Maria Tereza. O Envelhecimento Populacional na Agenda das Políticas Públicas. In: KANSO, Solange; LEITÃO, Juliana e Melo; PASINATO, Maria Tereza. Os Novos Idosos Brasileiros: Muito Além dos 60? Rio de Janeiro: IPEA, 2004. Google

CERQUEIRA, Marilia Barbosa Rodrigues. Envelhecimento populacional e população institucionalizada, um estudo de caso dos asilos do município de Montes Claros. Belo Horizonte: 2003. 109p. Dissertação (Mestrado em Demografia). Universidade Federal de Minas Gerais.

CHRISTOPHE, Micheline; CAMARANO, Ana Amélia. Dos asilos às instituições de longa permanência: uma história de mitos e preconceitos. In: CAMARANO, A.A. (Org.). Cuidados de longa duração a pessoa idosa: um novo risco social a ser assumido? Rio de Janeiro: IPEA, 2010 (350 p).

CREUTZBERG, Marion; GONÇALVES, Lúcia Hisako Takase; SOBOTTA, Emil Albert; SANTOS, Beatriz Regina Lara dos Santos. A comunicação entre a família e a Instituição para Idosos. Revista Brasileira Geriatria Gerontologia, v.10, n. 2. Rio de Janeiro,2007.

CREUTZBERG, Marion; SANTOS Beatriz Regina Lara dos. Famílias cuidadoras de pessoa idosa: relação com instituições sociais e de saúde. Rev. Bras. Enfermagem, 2003, novembrodezembro; v. 56, n. 6, p. 624-629. Ecrossret Google

COSTA, Maria Carla N.S; MERCADANTE, Elizabeth Fronhlich. O Idoso residente em ILPI (Instituição de Longa Permanência do Idoso) e o que isso representa para o sujeito idoso. Revista Kairós Gerontologia, v. 6, n. 2, p. 209-222. Março: 2013. Google

ESCORSIM, Silvana Maria. A filantropia no Brasil: entre a caridade e a política de assistência social. Revista Espaço Acadêmico, Maringá, Ano 8, n. 86, jul. 2008.

FABRÍCIO, Tamires Carolina Marques et al. Avaliação do caráter das organizações de consumo coletivo para idosos (as) da cidade e da região metropolitana do Recife - PE. In: III 
Congresso Internacional de Envelhecimento Humano - CIEH, 2013, Campina Grande PB. Ed. Realize, 2013.

FABRÍCIO, Tamires Carolina Marques; SARAIVA, Joseana Maria. Caracterização das Condições de habitabilidade na perspectiva dos (as) usuários (as) das Instituições de Longa Permanência para Idosos (as) da Cidade e Região Metropolitana do Recife-PE. In:

COMUNICON 2015- ESPM. São Paulo, 2015.

FERREIRA, Alida Rosaria Silva. Perspectivas da oferta de cuidadores informais da população idosa, Brasil 2000-2015. Dissertação (Mestrado em Demografia) - Centro de Desenvolvimento e Planejamento Regional, Universidade Federal de Minas Gerais, Belo Horizonte, 2007.

FILLIZOLA, Maria Lucia. A velhice no Brasil. Rio de Janeiro, CBAG: 1972.

GROINSMAN, Daniel. Asilos de velhos: passado e presente. In: Estudos interdisciplinares sobre o envelhecimento, Porto Alegre, 1999; v.2, p. 67-87.

LIMA, Claudia Regina Vieira. Políticas Públicas para Idosos: a realidade das instituições de longa permanência no Distrito Federal. Brasília - DF. Monografia (especialização). Curso em Legislação e Políticas públicas / Câmara dos Deputados/Centro de Formação, Treinamento e aperfeiçoamento (CEFOR), 2011.

MINISTÉRIO DA SAÚDE. Secretaria de Atenção à Saúde. Departamento de Ações Programáticas e Estratégicas. Atenção à saúde da pessoa idosa e envelhecimento/ Ministério da Saúde, Secretaria de Atenção à Saúde, Departamento de Ações Programáticas e Estratégicas, Área Técnica Saúde do Idoso. - Brasília, 2010. 44 p.: il. - (Série B. Textos Básicos de Saúde) (Série Pactos pela Saúde 2006, v. 12) ISBN 978-85-334-1620-8.

MOREIRA, Marilda da Silva. Qualidade de vida: Expressões Subjetivas e Histórico -Sociais. Sociais Serviço Social em Revista, v.9, n.1, jul./Dez., p.1-7, 2007. Google

NOVAES, Regina Helena Lasneaux. Os asilos de idosos no Estado do Rio de Janeiro repercussões da (não) integralidade no cuidado e na atenção à saúde dos idosos. Dissertação (Mestrado) - IMS, Universidade do Estado do Rio de Janeiro, Rio de Janeiro, 2003.

PEREIRA-PEREIRA, Potyara Amazoneida. Política de Assistência Social: avanços e retrocessos. In: Cadernos do CEAM n. 11. Brasília: CEAM/UnB, 2002.

PINTO, Silvia Patrícia Lima Castro; SIMSON, Olga Rodrigues de Morais Von. Instituições de Longa Permanência para Idosos no Brasil: Sumário da Legislação. Rev. Bras. Geriatr.

Gerontol, Rio de Janeiro, v. 15, n.1, p.169-174, 2012.

POLLO, Sandra Helena Lima; ASSIS, Mônica. Instituições de Longa Permanência para Idosos - ILPIs: desafios e alternativas no município do Rio de Janeiro. Revista Brasileira de Geriatria e Gerontologia, v.11, n. 1. Rio de Janeiro, 2008. Google

RIBEIRO, Adalgiza Peixoto; SCHUTZ, Gabriel Eduardo. Reflexões sobre o envelhecimento e bem-estar de idosas institucionalizadas. Rev. Bras. Geriatr. Gerontol., v. 10, n. 2, p. 191-201, 2007. Google 
RODRIGUES, Nara da Costa. Política Nacional do Idoso: retrospectiva histórica. Estud. interdiscip. envelhec., Porto Alegre, v.3, p.149-158, 2001. Google

RODRIGUES, Nara da Costa. PNI - Retrospectiva da política nacional do idoso. Revés do Avesso, v. 14, p. 84- 90, 2005.

SANTOS, Claudia Rodrigues de Souza dos. O idoso no Brasil: da velhice desamparada a velhice dos direitos. Monografia de Pós-Graduação Lato Sensu. Rio de Janeiro. Universidade Cândido Mendes, 2011.

SILVA, Carla Andrade; MENEZES, Maria do Rosário; SANTOS, Ana Carla Petersen de Oliveira; CARVALHO, Lucineide Santos; BARREIROS, Edileide Xavier. Relacionamento de amizade na instituição asilar. Rev. Gaúcha Enfermagem, Porto Alegre, v. 27, n. 2, p. 274-283, 2006. Google

SILVA, Kamilla Alexsandra; SILVA, Maria de Fátima Gomes da; MURTA, Nadja Maria Gomes (2013, setembro). Práticas alimentares e bem-estar de residentes de uma Instituição de Longa Permanência para Idosos da cidade de Diamantina (MG). Revista Kairós Gerontologia, v. 16, n. 3, p. 221-236, 2013. Google

SOUSA, Eldina Castro. Avaliação antropométrica e funcional de idosos residentes em Instituições de Longa Permanência no município de Teresina, PI. Teresina: 2008. 114p. Dissertação (Mestrado em Ciências da Saúde). Universidade Federal do Piauí. 